\title{
USO DE LODO DE ESGOTO ESTABILIZADO EM UM SOLO DECAPITADO. I - ATRIBUTOS FÍSICOS E REVEGETAÇÃO ${ }^{(1)}$
}

\author{
Alexandro Batista Ricci ${ }^{(2)}$, Vera Cristina Ramalho Padovani ${ }^{(3)}$ \& Durval \\ Rodrigues de Paula Júnior ${ }^{(4)}$
}

\begin{abstract}
RESUMO
A disposição do lodo de esgoto, estabilizado e tratado, em solos tem se mostrado uma alternativa viável, uma vez que pode ser feita com baixo custo e sem provocar impactos negativos, contribuindo também para o restabelecimento das características originais de alguns solos que sofreram processos de degradação. Com o objetivo de avaliar o uso de dosagens $\left(0,20,40\right.$ e $\left.80 \mathrm{Mg} \mathrm{ha}^{-1}\right)$ de um composto orgânico de lodo de esgoto e resíduos de roçagem na recuperação de um solo decapitado, pelo seu efeito nos atributos físicos do solo e revegetação com espécies nativas, realizou-se um experimento em Mogi-Guaçu - SP. Concluiu-se que as dosagens de lodo de esgoto compostado não modificaram os atributos físicos analisados no solo do local e que a altura e o diâmetro médio das plantas do reflorestamento escolhido não sofrem influência das dosagens crescentes de composto de lodo de esgoto no solo decapitado, independentemente do grupo sucessional.
\end{abstract}

Termos de indexação: resíduos sólidos, reflorestamento, solo degradado.

\section{SUMMARY: USE OF STABILIZED SEWAGE SLUDGE ON A HUMUSLESS SOIL. I - PHYSICAL PROPERTIES AND REVEGETATION}

The application of treated and stabilized sewage sludge to soils has been shown to be a viable disposal alternative, since costs are low and cause no negative impacts, but contribute to the restoration of the original characteristics of some degraded soils. This experiment was

\footnotetext{
(1) Parte da Tese de Doutorado do primeiro autor apresentada à Faculdade de Engenharia Agrícola - FEAGRI/UNICAMP. Recebido para publicação em março de 2009 e aprovado em janeiro de 2010.

(2) Engenheiro-Agrônomo, Prefeitura Municipal de Mogi-Guaçu - SP. Av. Mogi Mirim 93, CEP 13844-110 Mogi-Guaçu (SP). Email: alebatric@ig.com.br

(3) Doutoranda, Faculdade de Engenharia Agrícola - FEAGRI/UNICAMP. Cidade Universitária Zeferino Vaz, Av. Candido Rondon 501, Barão Geraldo, CEP 13083-875 Campinas (SP). E-mail: verapadovani@ig.com.br

(4) Professor Associado, Agricultura e Ambiente, FEAGRI/UNICAMP. E-mail: durval@agr.unicamp.br
} 
carried out in Mogi Guaçu, State of São Paulo (Brazil) to evaluate the effect of doses (0, 20, 40, and $80 \mathrm{Mg} \mathrm{ha}^{-1}$ ) of an organic compost of sewage sludge and grass residues on the recovery of a humusless soil, in particular on the soil physical properties and revegetation with native species. It was found that doses of sewage sludge compost did not change the soil physical properties at the site under study and the plant height and diameter of the chosen reforestation species were not influenced by increasing doses of sewage sludge compost applied to humusless soil, regardless of the succession group.

Index terms: Solid residues, reforestation, degraded soil.

\section{INTRODUÇÃO}

Atualmente, uma grande parte da população brasileira vive em cidades com mais de 20.000 habitantes, e uma das consequências dessa concentração populacional é o surgimento de diversos problemas ambientais relacionados com a geração de resíduos. Entre os prejuízos causados pela urbanização desordenada, podem-se citar a deterioração dos recursos hídricos e a degradação dos solos. As exigências crescentes da sociedade e das agências ambientais por melhores padrões de qualidade ambiental têm se refletido nos gestores públicos e privados dos serviços de saneamento; devido aos baixos índices de tratamento de esgotos, ainda verificados no País, há uma perspectiva de aumento significativo do número de estações de tratamento de esgotos e, em decorrência, da produção de lodo de esgoto.

A disposição do lodo de esgoto, estabilizado e tratado, em solos tem se mostrado uma alternativa viável, uma vez que pode ser feita com baixo custo e sem provocar impactos negativos, desde que realizada dentro de critérios seguros, contribuindo também para o restabelecimento das características originais de alguns solos que sofreram processos de degradação. A aplicação do lodo no solo não é um processo simples, dada a grande variação na sua composição e a complexidade dos diferentes tipos de solo.

Estudos que indicam o efeito da disposição desse resíduo no solo, nos diferentes componentes do sistema solo-planta-água, são ferramentas importantes para o uso sustentável. Em um experimento, Mello (2004) aplicou lodo de esgoto in natura em um Latossolo Vermelho distrófico durante cinco anos e observou que somente a dose acumulada de $50 \mathrm{Mg} \mathrm{ha}^{-1}$ reduziu a densidade do solo na camada de $0-0,10 \mathrm{~m}$, não alterando a densidade na camada de 0,10-0,40 m; esse autor concluiu também que os efeitos do lodo de esgoto nos atributos físicos do solo dependem do tipo de solo e da quantidade aplicada. Dados semelhantes foram descritos por Colino (2006), que, estudando o comportamento de solos com diferentes texturas em função da aplicação de lodo de esgoto, concluiu que o solo arenoso foi o que apresentou resultado melhor em seus aspectos físicos após a adição do lodo, em relação ao solo argiloso. O experimento objetivou avaliar o potencial de dosagens de um composto orgânico de lodo de esgoto e resíduos de roçagem na recuperação de um solo decapitado, por meio do efeito nos atributos físicos do solo e revegetação com espécies nativas.

\section{MATERIAL E MÉTODOS}

$\mathrm{O}$ experimento foi conduzido em uma área verde do município de Mogi-Guaçu, a qual apresenta o solo decapitado, pois sofreu a retirada de uma camada superficial de $2 \mathrm{~m}$ de espessura para a utilização em serviços de terraplenagem do local. O solo original é um Latossolo Vermelho-Amarelo distrófico ou álico textura argilosa leve, apresentando o relevo plano com declividade menor que $3 \%$; a vegetação original é a floresta estacional semidecidual.

O composto orgânico foi obtido pela compostagem, utilizando o processo de leiras revolvidas, de dois resíduos gerados no município de Mogi-Guaçu: lodo de esgoto obtido em sistema de lodos ativados por batelada (LAB) com aeração prolongada; e resíduos de roçagens de gramíneas (grama-batatais e Brachiaria ssp.) de parques, praças, canteiros centrais de avenidas e jardins públicos. O composto atendeu às exigências químicas da legislação (CONAMA, 2006) em vigor (Quadro 1).

Foram estabelecidos quatro tratamentos com diferentes dosagens de aplicação de composto no solo (Quadro 2) e plantio de árvores nativas, com quatro repetições por tratamento, totalizando 16 parcelas. $\mathrm{O}$ terreno foi subsolado, e as parcelas, demarcadas com a dimensão de $10 \times 10 \mathrm{~m}$, perfazendo $100 \mathrm{~m}^{2}$ por parcela e uma área total experimental de $1.600 \mathrm{~m}^{2}$, composta de 16 parcelas, segundo recomendação de Igue \& Lasca (1986). O composto foi aplicado manualmente nas parcelas, antes do plantio das mudas, em três aplicações iguais e intervaladas de um mês cada uma, seguidas de incorporação mecanizada, por meio de um gradeamento a $0,20 \mathrm{~m}$ de profundidade. Não foram realizadas reaplicações do composto de lodo de esgoto após o plantio.

Após a incorporação total do composto, foram realizados a abertura das covas e o plantio das árvores nativas conforme método proposto de Macedo (1993). $\mathrm{O}$ espaçamento foi de $2 \mathrm{~m}$ entre linhas e $2 \mathrm{~m}$ entre 
Quadro 1. Caracterização química do lodo de esgoto, do composto produzido no município de Mogi-GuaçuSP no ano de 2004 e os limites máximos permitidos pela legislação

\begin{tabular}{|c|c|c|c|}
\hline Atributo & Lodo & Composto & Conama (2006) \\
\hline pH (em água) & 7,1 & 6,0 & - \\
\hline Umidade (\%) & 87,8 & 18,3 & - \\
\hline Sólidos voláteis (\%) & 60,6 & 18,1 & - \\
\hline Carbono orgânico $\left(\mathrm{g} \mathrm{kg}^{-1}\right)$ & 356,3 & 75,3 & - \\
\hline Nitrogênio total $\left(\mathrm{g} \mathrm{kg}^{-1}\right)$ & 50,4 & 7,9 & - \\
\hline Nitrogênio amoniacal amoniacal $\left(\mathrm{mg} \mathrm{kg}^{-1}\right)$ & 365,3 & 7,0 & . \\
\hline Nitrogênio nitrato-nitrito $\left(\mathrm{mg} \mathrm{kg}^{-1}\right)$ & 12,0 & 23,3 & . \\
\hline Fósforo $\left(\mathrm{g} \mathrm{kg}^{-1}\right)$ & 11,1 & 1,6 & - \\
\hline Potássio (mg kg-1) & 1.500 & 1.377 & - \\
\hline Cálcio $\left(\mathrm{g} \mathrm{kg}^{-1}\right)$ & 10,6 & 2,4 & - \\
\hline Enxofre $\left(\mathrm{g} \mathrm{kg}^{-1}\right)$ & 7,0 & 1,0 & - \\
\hline Magnésio $\left(\mathrm{g} \mathrm{kg}^{-1}\right)$ & 1,5 & 0,86 & - \\
\hline Alumínio $\left(\mathrm{mg} \mathrm{kg}^{-1}\right)$ & 12.100 & 9.203 & . \\
\hline Arsênio $\left(\mathrm{mg} \mathrm{kg}^{-1}\right)$ & $<0,01$ & ND & 41 \\
\hline Boro $\left(\mathrm{mg} \mathrm{kg}^{-1}\right)$ & 1,5 & ND & - \\
\hline Cádmio $\left(\mathrm{mg} \mathrm{kg}^{-1}\right)$ & 1,5 & ND & 39 \\
\hline Chumbo (mg kg-1) & 45,6 & ND & 300 \\
\hline Cobre $\left(\mathrm{mg} \mathrm{kg}^{-1}\right)$ & 219,0 & 31,5 & 1.500 \\
\hline Cromo total $\left(\mathrm{mg} \mathrm{kg}^{-1}\right)$ & 25,2 & ND & 1.000 \\
\hline Ferro $\left(\mathrm{mg} \mathrm{kg}^{-1}\right)$ & 24.900 & 9.716 & - \\
\hline Manganês ( $\left.\mathrm{mg} \mathrm{kg}^{-1}\right)$ & 108,2 & 127,8 & - \\
\hline Mercúrio $\left(\mathrm{mg} \mathrm{kg}^{-1}\right)$ & $<0,01$ & ND & 17 \\
\hline Molibdênio $\left(\mathrm{mg} \mathrm{kg}^{-1}\right)$ & $<0,01$ & 7,9 & 50 \\
\hline Níquel $\left(\mathrm{mg} \mathrm{kg}^{-1}\right)$ & 13,4 & 16,3 & 420 \\
\hline Selênio $\left(\mathrm{mg} \mathrm{kg}^{-1}\right)$ & $<0,01$ & ND & 100 \\
\hline Sódio (mg kg-1) & 300 & 5,6 & - \\
\hline Zinco $\left(\mathrm{mg} \mathrm{kg}^{-1}\right)$ & 550,0 & 97,4 & 2.800 \\
\hline
\end{tabular}

ND: não detectado (concentrações menores que $1 \mathrm{mg} \mathrm{kg}^{-1}$ ).

Quadro 2. Dosagens de composto de lodo de esgoto utilizadas nos tratamentos, parceladas em três vezes

\begin{tabular}{|c|c|c|c|c|c|}
\hline \multirow[t]{2}{*}{ Tratamento } & \multirow{2}{*}{$\begin{array}{c}1^{\text {a }} \text { aplicação } \\
\text { Ago/2005 }\end{array}$} & \multirow{2}{*}{$\begin{array}{c}2^{\text {a }} \text { aplicação } \\
\text { Set/2005 }\end{array}$} & \multirow{2}{*}{$\begin{array}{c}3^{\underline{a}} \text { aplicação } \\
\text { Out/2005 }\end{array}$} & \multicolumn{2}{|c|}{ Total por parcela } \\
\hline & & & & $\mathrm{kg}$ & $\mathrm{Mg} \mathrm{ha}^{-1}$ \\
\hline T0 & 0 & 0 & 0 & 0 & 0 \\
\hline $\mathrm{T} 1$ & 67 & 67 & 66 & 200 & 20 \\
\hline $\mathrm{T} 2$ & 134 & 134 & 133 & 400 & 40 \\
\hline $\mathrm{T} 3$ & 267 & 267 & 266 & 800 & 80 \\
\hline
\end{tabular}

plantas, obtendo-se uma densidade populacional de 2.500 árvores ha ${ }^{-1}$, sendo 25 por parcela. Nesse método, uma linha de espécies pioneiras $(\mathrm{P})$ alternase com uma linha de espécies não pioneiras (NP), trabalhando-se com 20 espécies diferentes no total (Figura 1).

As amostragens foram realizadas antes da implantação do experimento, antes do plantio, um ano após o plantio das mudas e no final de dois anos do plantio. As amostras destinadas às análises físicas foram coletadas a partir do método do anel volumétrico, nas profundidades de 0-0,20 e 0,20-
0,40 m, com três repetições por parcela, em quatro épocas distintas: antes da implantação, após o plantio e anualmente, até a finalização dois anos após o plantio.

A porosidade total, macroporosidade e microporosidade, em percentagens, foram determinadas segundo métodos recomendados por Vomocil (1965) e Leaner \& Shaw (1941), modificados por Kiehl (1979), pelo método da mesa de tensão. Na determinação da densidade global foi utilizado o método de Blake (1965). A distribuição e estabilidade dos agregados foram obtidas a partir do método descrito por Kiehl (1979), utilizando peneira para agitação dos agregados em água. 


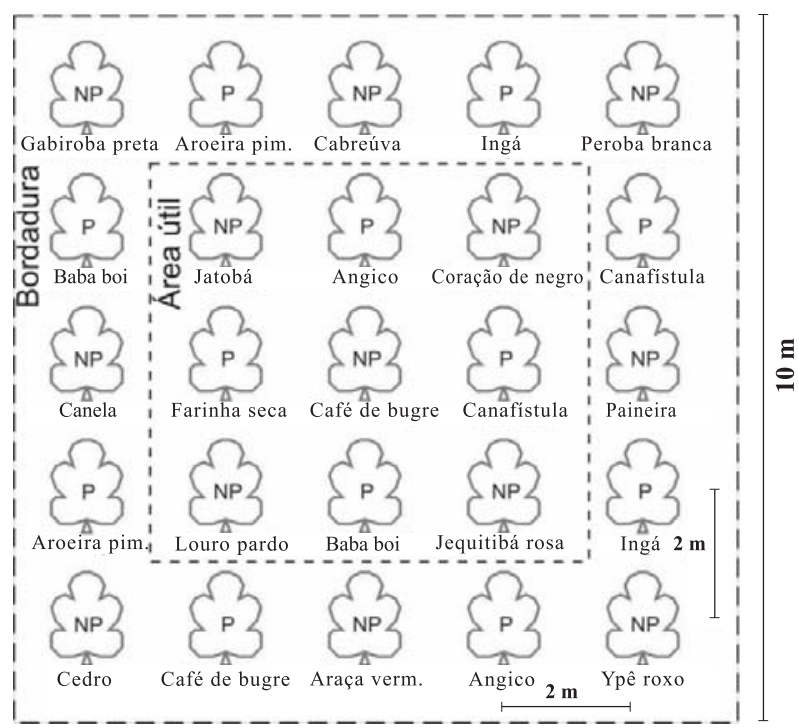

Figura 1. Esquema de uma parcela, delimitando o espaçamento de plantio, as bordaduras e as espécies utilizadas (NP: não pioneira, P: pioneira).

Foram avaliados a altura das plantas e o diâmetro do fuste a $0,30 \mathrm{~m}$ do solo, utilizando-se trena e paquímetro para cada espécie, para então determinar a altura média e o diâmetro médio.

As determinações nas árvores foram feitas após o plantio, no primeiro e segundo anos pós-plantio. O delineamento estatístico foi o de parcelas subdivididas e blocos ao acaso, com quatro tratamentos e quatro repetições, totalizando 16 parcelas. Utilizou-se o software SISVAR para processamento dos dados. O teste $\mathrm{F}$ foi aplicado. Quando constatada interação significativa, as médias foram testadas dentro de doses, por modelos de regressão polinomial de $1^{\circ}, 2^{\circ}$ ou $3^{\circ}$ grau, e dentro de períodos, pelo teste de Tukey a $\mathrm{p} \leq 0,05$.

\section{RESULTADOS E DISCUSSÃO}

A densidade do solo não apresentou diferenças significativas com a aplicação de doses do composto de lodo de esgoto nas duas profundidades estudadas, durante o período de duração do experimento, em comparação com a testemunha (Quadro 3).

A mesma situação foi observada por Andrade et al. (2005), que, determinando o efeito da aplicação em cobertura de doses de um lodo de esgoto alcalino após cinco anos, em um Latossolo Vermelho-Amarelo distrófico cultivado com eucalipto, relataram que não foram encontradas diferenças significativas entre os tratamentos para a densidade do solo do experimento até a profundidade de $0,60 \mathrm{~m}$. Os resultados também corroboram o experimento de Boeira \& Souza (2007) e Jorge et al. (1991). Na camada de 0 a 0,20 m, logo após as aplicações, obtiveram-se as menores densidades, e estas aumentaram até dois anos depois, sendo significativamente maiores. Na camada de 0,20$0,40 \mathrm{~m}$ não houve alterações na densidade do solo durante o tempo de estudo (Quadro 3).

Os efeitos observados na densidade do solo na camada de 0-0,20 m, independentemente da dosagem do composto de lodo de esgoto, provavelmente deveramse ao preparo do solo com subsolagem e às operações com grades realizadas durante as incorporações do composto, as quais promoveram revolvimento do solo e rearranjo das partículas; o solo tendeu a voltar para a condição inicial com o decorrer do tempo. As mesmas observações foram feitas por Kitamura et al. (2008) e Colodro (2006).

$\mathrm{Na}$ camada de 0-0,20 m não foram observadas alterações significativas na porosidade total nas parcelas que receberam as doses do composto de lodo de esgoto. A porosidade total do solo pode não sofrer efeito significativo da adição de lodo de esgoto, segundo observações de Furrer \& Stauffer (citado por Jorge et

Quadro 3. Densidade do solo nas profundidades de 0-0,20 e 0,20-0,40 m, de um Latossolo Vermelho-Amarelo decapitado, após aplicação de diferentes dosagens de composto de lodo de esgoto, em três épocas distintas

\begin{tabular}{|c|c|c|c|c|c|c|}
\hline \multirow{2}{*}{ Dosagem de aplicação } & \multicolumn{3}{|c|}{ Densidade do solo $(0-0,20 \mathrm{~m})$} & \multicolumn{3}{|c|}{ Densidade do solo $(0,20-0,40 \mathrm{~m})$} \\
\hline & 0 ano & 1 ano & 2 ano & 0 ano & 1 ano & 2 ano \\
\hline \multicolumn{7}{|l|}{$\mathrm{Mg} \mathrm{ha}^{-1}$} \\
\hline 0 & 1,28 & 1,34 & 1,38 & 1,39 & 1,48 & 1,37 \\
\hline 20 & 1,33 & 1,37 & 1,33 & 1,43 & 1,44 & 1,42 \\
\hline 40 & 1,29 & 1,33 & 1,42 & 1,39 & 1,49 & 1,42 \\
\hline 80 & 1,28 & 1,37 & 1,45 & 1,46 & 1,45 & 1,42 \\
\hline \multirow[t]{2}{*}{ Média } & $1.30 \mathrm{~B}$ & $1.35 \mathrm{~A}$ & $1.40 \mathrm{~A}$ & $1.42 \mathrm{~A}$ & $1.47 \mathrm{~A}$ & $1.41 \mathrm{~A}$ \\
\hline & & Prob F & $\mathrm{CV}$ & & Prob F & CV \\
\hline Dose & & NS & 9,57 & & NS & 14,61 \\
\hline Período & & $* *$ & 7,55 & & NS & 8,46 \\
\hline Dose $\mathrm{x}$ Período & & NS & $\cdots$ & & NS & $\cdots$ \\
\hline
\end{tabular}

Médias seguidas da mesma letra não diferem a $5 \%$ pelo teste de Tukey; letras maiúsculas comparam médias totais de períodos. (NS: não significativo; * $\mathrm{e}^{* *}$, significativos a 5 e $1 \%$, respectivamente). 
al., 1991), devido às condições originais do solo. Logo após a aplicação do composto de lodo de esgoto e plantio, a porosidade total das parcelas foi estatisticamente menor que dois anos depois (Quadro 4). Assim como observado na densidade do solo, a porosidade também teve influência do revolvimento do solo no momento da incorporação do composto de lodo de esgoto, tendendo aos valores originais com o decorrer do tempo.

Na camada de 0-0,20 m, as diferentes dosagens de composto de lodo de esgoto alteraram significativamente a macroporosidade do solo nas parcelas (Quadro 4). O ajuste matemático dos valores observados foi adequado $\left(\mathrm{R}^{2}=1,00\right)$ (Figura 2$)$, mostrando uma tendência de aumento da macroporosidade com o aumento da dose de composto de lodo de esgoto e que a dose de $40 \mathrm{Mg} \mathrm{h}^{-1}$ foi a que proporcionou as maiores médias de macroporosidade.

A microporosidade não foi alterada pelas diferentes dosagens de composto de lodo de esgoto aplicadas no experimento (Quadro 4).
A ausência de resposta do solo pela aplicação de lodo de esgoto nas suas características físicas também foi descrita em alguns trabalhos encontrados na literatura, como os de Colodro (2006), Camilotti et al. (2006) e Kitamura et al. (2008).

Na camada de 0,20-0,40 m, tanto a macroporosidade como a microporosidade do solo sofreram alterações significativas na camada inicial ao longo da fase experimental (Quadro 4). Os menores valores de macroporosidade e os maiores de microporosidade foram obtidos após dois anos das aplicações de composto de lodo de esgoto, independentemente das dosagens.

Logo após o parcelamento das aplicações do composto de lodo de esgoto e o plantio das mudas, apesar de o teste estatístico não indicar diferenças, nota-se uma tendência de aumento da macroporosidade e diminuição da microporosidade com o aumento crescente das doses de aplicação do composto de lodo de esgoto. Uma hipótese para explicar o ocorrido é que o efeito máximo da matéria orgânica no solo

Quadro 4. Porosidade total, macroporosidade e microporosidade em duas profundidades de um Latossolo Vermelho-Amarelo decapitado, após aplicação de diferentes dosagens de composto de lodo de esgoto, em três épocas distintas

\begin{tabular}{|c|c|c|c|c|c|c|}
\hline \multirow{2}{*}{ Dosagem de aplicação } & \multicolumn{3}{|c|}{ Profundidade $(0-0,20 \mathrm{~m})$} & \multicolumn{3}{|c|}{ Profundidade $(0,20-0,40 \mathrm{~m})$} \\
\hline & 0 ano & 1 ano & 2 ano & 0 ano & 1 ano & 2 ano \\
\hline \multirow[t]{2}{*}{$\mathrm{Mg} \mathrm{ha}^{1}$} & \multicolumn{6}{|c|}{$\mathrm{kg} \mathrm{dm}{ }^{-3}$} \\
\hline & \multicolumn{6}{|c|}{ Porosidade total } \\
\hline 0 & 0,453 & 0,470 & 0,439 & 0,420 & 0,434 & 0,443 \\
\hline 20 & 0,439 & 0,466 & 0,440 & 0,421 & 0,436 & 0,442 \\
\hline 40 & 0,459 & 0,480 & 0,428 & 0,430 & 0,435 & 0,433 \\
\hline 80 & 0,467 & 0,460 & 0,425 & 0,405 & 0,414 & 0,430 \\
\hline \multirow[t]{2}{*}{ Média } & $0,454 \mathrm{~A}$ & $0,470 \mathrm{~A}$ & $0,433 \mathrm{~B}$ & $0,419 \mathrm{~A}$ & $0,429 \mathrm{~A}$ & $0,437 \mathrm{~A}$ \\
\hline & & Prob F & CV & & Prob F & CV \\
\hline Dose & & NS & 10,46 & & NS & 9,72 \\
\hline Per íodo & & $* *$ & 8,61 & & NS & 9,16 \\
\hline Dose x Período & & NS & --- & & NS & -- \\
\hline & \multicolumn{6}{|c|}{ Macroporosidade } \\
\hline 0 & 0,114 & 0,163 & $0,079^{\text {Nid }}$ & 0,084 & 0,083 & 0,075 \\
\hline 20 & 0,110 & 0,140 & 0,085 & 0,080 & 0,084 & 0,068 \\
\hline 40 & 0,151 & 0,145 & 0,088 & 0,099 & 0,105 & 0,076 \\
\hline 80 & 0,144 & 0,136 & 0,077 & 0,085 & 0,107 & 0,076 \\
\hline \multirow[t]{2}{*}{ Média } & $0,130 \mathrm{~B}$ & $0,147 \mathrm{~A}$ & $0,082 \mathrm{C}$ & $0086 \mathrm{AB}$ & $0,094 \mathrm{~A}$ & $0,074 \mathrm{~B}$ \\
\hline & & Prob F & CV & & Prob F & CV \\
\hline Dose & & * & 16,29 & & NS & 42,25 \\
\hline Per íodo & & $* *$ & 29,73 & & * & 41,68 \\
\hline $\begin{array}{l}\text { Perlodo } \\
\text { Dose x Período }\end{array}$ & \multirow{2}{*}{\multicolumn{6}{|c|}{ Microporosidade }} \\
\hline Dose X rerrodo & & & & & & \\
\hline 0 & 0,340 & 0,307 & 0,360 & 0,335 & 0,351 & 0,369 \\
\hline 20 & 0,329 & 0,327 & 0,355 & 0,342 & 0,352 & 0,374 \\
\hline 40 & 0,310 & 0,336 & 0,336 & 0,331 & 0,330 & 0,356 \\
\hline 80 & 0,323 & 0,324 & 0,348 & 0,320 & 0,308 & 0,354 \\
\hline \multirow[t]{2}{*}{ Média } & $0,325 \mathrm{~B}$ & $0,323 \mathrm{~B}$ & $0,351 \mathrm{~A}$ & $0,333 \mathrm{~B}$ & $0,335 \mathrm{~B}$ & $0,363 \mathrm{~A}$ \\
\hline & & Prob F & $\mathrm{CV}$ & & Prob F & $\mathrm{CV}$ \\
\hline Dose & & NS & 11,65 & & $* *$ & 9,46 \\
\hline Período & & $* *$ & 11,07 & & $* *$ & 9,93 \\
\hline Dose x Período & & NS & -- & & NS & -- \\
\hline
\end{tabular}

Médias seguidas da mesma letra não diferem a $5 \%$ pelo teste de Tukey; letras maiúsculas comparam médias totais de períodos. (NS: não significativo; * $\mathrm{e}^{* *}$, significativos a 5 e $1 \%$, respectivamente). 


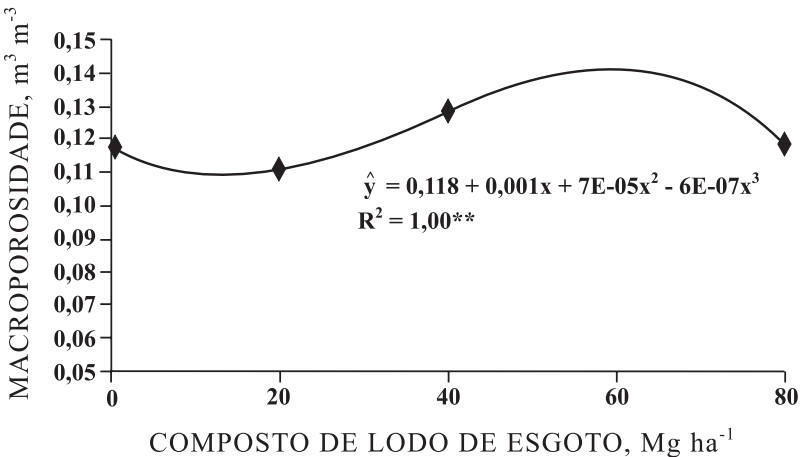

Figura 2. Análise de regressão para macroposidade do solo em função das doses crescentes de composto de lodo de esgoto, na camada de 0 $0,20 \mathrm{~m}(* *=$ significativo a $1 \%)$.

ocorreu logo após as aplicações; com o passar do tempo cessou-se o efeito condicionador da matéria orgânica devido à quase total mineralização da fração orgânica, levando novamente esses parâmetros físicos próximos à condição inicial do experimento.

Segundo Kiehl (1985), a matéria orgânica do solo é oxidada com maior intensidade em climas tropicais e subtropicais, sendo difícil elevar o teor de húmus do solo nessas condições.

Na camada de 0,20-0,40 m, a porosidade total do solo não demonstrou diferença estatística significativa tanto para as dosagens do composto como para o período estudado, e a macroporosidade somente diferiu estatisticamente após dois anos, momento em que atingiu o menor valor, sem contudo apresentar diferenças entre as dosagens de composto de lodo de esgoto (Quadro 4).

As diferentes dosagens do composto de lodo de esgoto levaram a variações significativas na microporosidade na camada mais profunda estudada, sendo diminuída com o aumento das doses de composto de lodo de esgoto, apresentando alta correlação $\left(R^{2}=\right.$ $0,827)$. Uma hipótese para o fato é o efeito de lixiviados da camada acima, a qual recebeu as aplicações do composto de lodo de esgoto (Figura 3).

As observações de microporosidade do solo apresentadas no quadro 4 e obtidas no segundo ano foram diferentes das constatadas anteriormente, tendo apresentado as maiores médias. Assim como a macroporosidade, a microporosidade da camada inferior provavelmente foi alterada pela operação de subsolagem, a qual atingiu essa profundidade, causando modificações que tenderam à situação inicial do solo no decorrer do período.

A estrutura do solo, resultante da agregação, não foi alterada pelas diferentes doses de composto de lodo de esgoto aplicadas, durante os dois anos de estudos na camada de 0-0,20 m (Quadro 5). Resultados similares são observados por Carvalho (2006) e Campos (2005). Na camada inferior, de 0,20-0,40 m, as dosagens de aplicação não causaram diferenças

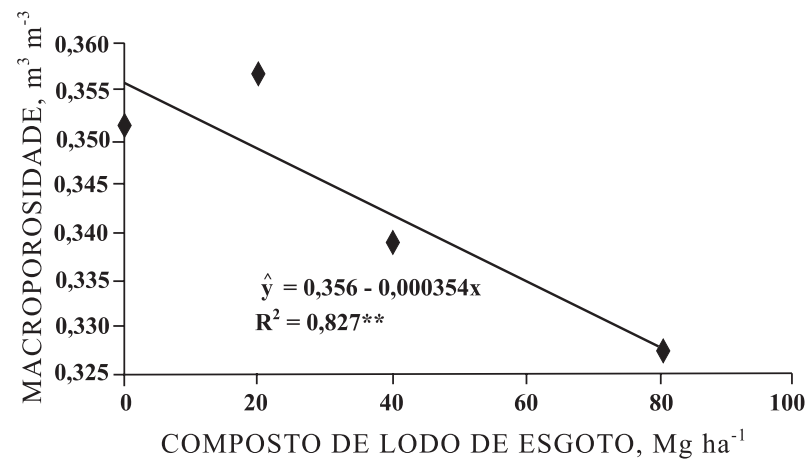

Figura 3. Médias da microposidade do solo, na camada de $0,20-0,40 \mathrm{~m}$, e análise da regressão em função das diferentes doses de composto de lodo de esgoto (** = significativo a $1 \%$ ).

Quadro 5. Diâmetro médio ponderado (DMP) dos agregados de um Latossolo Vermelho-Amarelo decapitado, após aplicação de diferentes dosagens de composto de lodo de esgoto, em três épocas distintas

\begin{tabular}{|c|c|c|c|c|c|c|}
\hline \multirow{2}{*}{ Dosagem de aplicação } & \multicolumn{3}{|c|}{$\begin{array}{l}\text { Diâmetro médio ponderado (DMP) } \\
\text { dos agregados de solo }(0-0,20 \mathrm{~m})\end{array}$} & \multicolumn{3}{|c|}{$\begin{array}{l}\text { Diâmetro médio ponderado (DMP) } \\
\text { dos agregados de solo }(0,20-0,40 \mathrm{~m})\end{array}$} \\
\hline & 0 ano & 1 ano & 2 ano & 0 ano & 1 ano & 2 ano \\
\hline \multicolumn{7}{|l|}{$\mathrm{Mg} \mathrm{ha}^{-1}$} \\
\hline 0 & 2,14 & 2,20 & 2,07 & 2,06 & 1,54 & 1,41 \\
\hline 20 & 2,28 & 2,05 & 2,18 & 1,81 & 1,25 & 1,43 \\
\hline 40 & 2,42 & 2,27 & 2,46 & 1,86 & 1,73 & 1,79 \\
\hline 80 & 2,11 & 2,11 & 2,17 & 1,93 & 1,69 & 1,41 \\
\hline \multirow[t]{2}{*}{ Média } & $2,24 \mathrm{~A}$ & $2,16 \mathrm{~A}$ & $2,22 \mathrm{~A}$ & $1,91 \mathrm{~A}$ & $1,55 \mathrm{~B}$ & $1,51 \mathrm{~B}$ \\
\hline & & Prob F & CV & & Prob F & $\mathrm{CV}$ \\
\hline Dose & & NS & 22,27 & & NS & 27,70 \\
\hline Período & & NS & 16,36 & & $* *$ & 26,15 \\
\hline Dose $x$ Período & & NS & -- & & NS & \\
\hline
\end{tabular}

Médias seguidas da mesma letra não diferem a $5 \%$ pelo teste de Tukey; letras maiúsculas comparam médias totais de períodos. (NS: não significativo; * $\mathrm{e}^{* *}$, significativos a 5 e $1 \%$, respectivamente). 
significativas no diâmetro dos agregados. Verificouse que durante o período estudado, independentemente das dosagens, o diâmetro médio dos agregados foi maior logo após as aplicações; um e dois anos depois, o valor diminuiu significativamente, assim como observado nas médias de macroporosidade do solo nessa camada. Esse efeito pode ter ocorrido devido à presença de lixiviados com características dispersantes, provenientes da camada superior.

Alguns autores constataram que a aplicação de lodo aumentou significativamente a agregação do solo na camada de 0-0,1 m, e as mais profundas, até 0,40 m, não sofreram alterações (Souza et al., 2005; Maria, 2007).

Os resultados médios de crescimentos das árvores, expressos pela altura e diâmetro do caule, não mostraram diferenças estatísticas significativas em função das diferentes dosagens de composto de lodo de esgoto testadas (Quadro 6). Entretanto, todas as características aumentaram significativamente ao longo do período estudado, indicando que as árvores desenvolveram-se na área de estudo, independentemente da dose de composto de lodo de esgoto. Resultados semelhantes foram obtidos por Bezerra et al. (2006).

As espécies pioneiras não apresentaram resposta significativa na altura e no diâmetro do caule para as diferentes dosagens de composto de lodo de esgoto (Quadro 7), demonstrando que as espécies pertencentes a esse grupo não responderam ao incremento de nutrientes no solo proporcionado pela adição de composto de lodo de esgoto (Quadro 1). Resultados indicando a baixa resposta de algumas árvores à fertilização do solo são descritos por Bordini (2007) e Gonçalves et al. (1992) citado por Venturin et al. (1999). As espécies pioneiras apresentaram a altura e o diâmetro do caule significativamente diferentes entre os períodos estudados, independentemente da dosagem de composto de lodo de esgoto (Quadro 7). Entretanto, o composto de lodo de esgoto não alterou significativamente a altura e o diâmetro das espécies não pioneiras durante o período estudado (Quadro 7). Segundo Barbosa

Quadro 6. Altura e diâmetro médio do caule das árvores implantadas em solo sob diferentes dosagens de composto de lodo de esgoto, mensurados em três períodos distintos

\begin{tabular}{|c|c|c|c|c|c|c|}
\hline \multirow{2}{*}{ Dosagem de aplicação } & \multicolumn{3}{|c|}{ Altura } & \multicolumn{3}{|c|}{ Diâmetro do caule } \\
\hline & 0 ano & 1 ano & 2 ano & 0 ano & 1 ano & 2 ano \\
\hline \multicolumn{7}{|l|}{$\mathrm{Mg} \mathrm{ha}{ }^{-1}$} \\
\hline 0 & 677 & 1.039 & 1.282 & 4,4 & 11,5 & 18,4 \\
\hline 20 & 662 & 1.196 & 1.372 & 4,3 & 14,0 & 23,2 \\
\hline 40 & 659 & 1.006 & 1.206 & 4,1 & 11,6 & 18,9 \\
\hline 80 & 632 & 1.155 & 1.274 & 4,1 & 13,6 & 21,9 \\
\hline \multirow[t]{2}{*}{ Médias } & $657 \mathrm{C}$ & $1.099 \mathrm{~B}$ & $1.283 \mathrm{~A}$ & $4,2 \mathrm{C}$ & $12,7 \mathrm{~B}$ & $20,6 \mathrm{~A}$ \\
\hline & & Prob F & CV & & Prob F & CV \\
\hline Dose & & NS & 23,71 & & NS & 38,86 \\
\hline Período & & $* *$ & 11,78 & & $* *$ & 22,42 \\
\hline Dose x Período & & NS & & & NS & --- \\
\hline
\end{tabular}

Médias seguidas da mesma letra não diferem a $5 \%$ pelo teste de Tukey; letras maiúsculas comparam médias totais de períodos. (NS: não significativo; ${ }^{*} \mathrm{e}^{* *}$, significativos a 5 e $1 \%$, respectivamente).

Quadro 7. Altura e diâmetro do caule das árvores pioneiras e não pioneiras implantadas em solo sob diferentes dosagens de composto de lodo de esgoto, mensurados em três períodos distintos

\begin{tabular}{|c|c|c|c|c|c|c|c|c|c|c|c|c|}
\hline \multirow{3}{*}{$\begin{array}{l}\text { Dosagem de } \\
\text { aplicação }\end{array}$} & \multicolumn{6}{|c|}{ Pioneiras } & \multicolumn{6}{|c|}{ Não pioneiras } \\
\hline & \multicolumn{3}{|c|}{ Altura } & \multicolumn{3}{|c|}{ Diâmetro do caule } & \multicolumn{3}{|c|}{ Altura } & \multicolumn{3}{|c|}{ Diâmetro do caule } \\
\hline & 0 ano & 1 ano & 2 ano & 0 ano & 1 ano & 2 ano & 0 ano & 1 ano & 2 ano & 0 ano & 1 ano & 2 ano \\
\hline \multicolumn{13}{|l|}{$\mathrm{Mg} \mathrm{ha}^{-1}$} \\
\hline 0 & 764 & 1354 & 1672 & 4,1 & 14,9 & 24,3 & 608 & 752 & 880 & 4,6 & 8,6 & 12,5 \\
\hline 20 & 609 & 1487 & 1691 & 3,5 & 18,7 & 34,7 & 701 & 963 & 1094 & 5,0 & 10,0 & 13,3 \\
\hline 40 & 653 & 1211 & 1499 & 3,7 & 15,8 & 28,5 & 663 & 867 & 955 & 4,4 & 8,8 & 10,4 \\
\hline 80 & 629 & 1434 & 1642 & 3,5 & 18,1 & 32,6 & 633 & 910 & 950 & 4,5 & 9,6 & 12,5 \\
\hline \multirow[t]{2}{*}{ Médias } & $664 \mathrm{C}$ & $1372 B$ & $1626 \mathrm{~A}$ & $3,7 \mathrm{C}$ & $16,9 \mathrm{~B}$ & $30,0 \mathrm{~A}$ & $651 \mathrm{C}$ & $873 \mathrm{~B}$ & $970 \mathrm{~A}$ & $4,6 \mathrm{C}$ & $9,22 \mathrm{~B}$ & $12,2 \mathrm{~A}$ \\
\hline & & Prob F & $\mathrm{CV}$ & & Prob F & $\mathrm{CV}$ & & Prob F & $\mathrm{CV}$ & & Prob F & $\mathrm{CV}$ \\
\hline Dose & & NS & 36,14 & & NS & 50,81 & & NS & 22,17 & & NS & 32,79 \\
\hline Período & & $* *$ & 17,67 & & $* *$ & 30,31 & & $* *$ & 11,59 & & $* *$ & 19,06 \\
\hline Dose x Período & & NS & -- & & NS & --- & & NS & -- & & NS & --- \\
\hline
\end{tabular}

Médias seguidas da mesma letra não diferem a $5 \%$ pelo teste de Tukey; letras maiúsculas comparam médias totais de períodos. (NS: não significativo; * $\mathrm{e}^{* *}$, significativos a 5 e $1 \%$, respectivamente). 
(2003), o grupo das árvores não pioneiras é tolerante ao sombreamento durante seu crescimento inicial; contudo, por estar nessa fase a pleno sol, pode ter seu desenvolvimento prejudicado.

Tanto a altura como o diâmetro do caule das não pioneiras aumentaram significativamente ao longo do período estudado (Quadro 7), mostrando o desenvolvimento desse grupo, o qual se caracteriza pela lentidão.

\section{CONCLUSÕES}

1. Os atributos físicos analisados no solo do local não apresentaram alterações significativas com as aplicações de lodo de esgoto compostado.

2. A altura e o diâmetro médio das plantas do reflorestamento escolhido não são influenciados pelas dosagens crescentes de composto de lodo de esgoto no solo decapitado; os grupos sucessionais estudados (pioneiras e não pioneiras) mostraram comportamentos semelhantes.

3. O uso de composto de lodo de esgoto na recuperação de um solo decapitado, por meio da revegetação com espécies nativas, é uma alternativa para o município de Mogi-Guaçu, no que se refere à sua disposição e recuperação de áreas degradadas.

\section{LITERATURA CITADA}

ANDRADE, C.A.; OLIVEIRA, C.D. \& CERRI, C.C. Qualidade da matéria orgânica e estoques de carbono e nitrogênio em Latossolo tratado com biossólido e cultivado com eucalipto. R. Bras. Ci. Solo, 29:803-816, 2005.

BARBOSA, L.M. Sucessão vegetal e modelos de recuperação. In: SEMINÁRIO REGIONAL SOBRE RECUPERAÇÃO DE ÁREAS DEGRADADAS: SUBSÍDIOS PARA A CONSERVAÇÃO DA BIODIVERSIDADE E MANUTENÇÃO DOS SISTEMAS HÍDRICOS. Mogi-Guaçu, 2003. 41p.

BEZERRA, F.B.; OLIVEIRA, M.A.; PEREZ, D.V. \& MENEGUELLI, A.G. Lodo de esgoto em revegetação de área degradada. Pesq. Agropec. Bras., 41:469-476, 2006.

BLAKE, G.R. Bulk density. In: BLACK, C.A., ed. Methods of soil analysis. Madison, American Society of Agronomy, 1965. p.374-390.

BOEIRA, R.C. \& SOUZA, M.D. Estoques de carbono orgânico e nitrogênio, $\mathrm{pH}$ e densidade de um Latossolo após três aplicações de lodo de esgoto. R. Bras. Ci. Solo, 31:581-590, 2007.

BORDINI, M.C. Manejo da regeneração natural de vegetação de cerrado, em áreas de paisagem, como estratégia de restauração na fazenda Santa Maria da Jauru, município de Porto Esperidião. Piracicaba, Escola Superior de Agricultura Luiz de Queiroz, 2007. 92p. (Tese de Mestrado)

CAMILOTTI, F.; ANDREOLI, I. \& MARQUES, M.O. Atributos físicos de um Latossolo cultivado com cana-de-aç[ucar após aplicações de lodo de esgoto e vinhaça. Eng. Agríc., 3:738-747, 2006
CAMPOS, F.S. Uso de lodo de esgoto na reestruturação de um Latossolo Vermelho degradado. Ilha Solteira, Universidade Estadual Paulista, 2005. 106p. (Tese de Mestrado)

CARVALHO, J.C. Condição dos agregados e da constituição microbiológica de solos submetidos a diferentes usos e manejos agrícolas em Selverínia. Campinas, Universidade Estadual de Campinas, 2006. 97p. (Tese de Mestrado)

COLINO, M.D. Uso de lodo de esgoto de estações de tratamento de água e esgoto como condicionador de solo, com ênfase nas propriedades físicas do solo. Botucatu, Universidade Estadual Paulista, 2006. 116p. (Tese de Doutorado)

COLODRO, G. Recuperação de solo de área de empréstimo com lodo de esgoto. Campinas, Universidade Estadual de Campinas, 2006. 82p. (Tese de Doutorado)

CONSELHO NACIONAL DE MEIO AMBIENTE - CONAMA. Resolução 375/06 - Critérios e procedimentos, para o uso agrícola de lodos de esgoto gerados em estações de tratamento de esgoto sanitário e seus produtos derivados, 32p, Brasília, 2006.

IGUE, T. \& LASCA, D.H. Experimentação de campo. Campinas, Coordenadoria de Assistência Técnica Integral, 1986. 32p. (Boletim Técnico)

JORGE. J.A.; CAMARGO. O.A. \& VALADARES, J.M.A.S Condições físicas de um Latossolo Vermelho-Escuro quatro anos após aplicação de lodo de esgoto e calcário. R. Bras. Ci. Solo, 15:237-240, 1991.

KIEHL, E.J. Fertilizantes orgânicos. Piracicaba, Agronômica Ceres, 1985. 468p.

KIEHL, E.J. Manual de edafologia: Relação solo-água-planta. São Paulo, Agronômica Ceres, 1979. 262p.

KITAMURA, A.E.; ALVES, M.C.; GUSTAVO, L. \& GONZALEZ, A.S. Recuperação de um solo degradado com aplicação de adubos verdes e lodo de esgoto. R. Bras. Ci. Solo, 32:405-416, 2008.

LEANER, R.W. \& SHAW, B.A. A simple apparatus of measuring non-capilary porosity on an extensive scale. J. Am. Soc. Agron., 33:1003-1008, 1941.

MACEDO, A.C.; KAGEYAMA, P.Y. \& COSTA, L.G.S Revegetação: Matas ciliares e de proteção ambiental. São Paulo, Fundação Florestal, 1993. 26p.

MARIA, I.C.; KOCSSI, M.A. \& DECHEN, S.C. Agregação do solo em área que recebeu lodo de esgoto. Bragantia, 66:291-298, 2007.

MELLO, V.E. Atributos físicos de Latossolos adubados durante cinco anos com biossólido. Pesq. Agropec. Bras., 39:67-72, 2004.

SOUZA, Z.M.; BEUTLER, A.N.; MELO, V.P. \& MELO, W.J. Estabilidade de agregados e resistência à penetração em Latossolos adubados por cinco anos com biossólidos. R. Bras. Ci. Solo, 29:117-123, 2005.

VENTURIN, N.; DUBOV, E.; VALE, F.R. \& DAVIDE, A.C. Adubação mineral do angico-amarelo Peltophorum dubium (SPRENG.) TAUB.). Pesq. Agropec. Bras., 34:441448,1999

VOMOCIL, J.A. Porosity. In: BLACK, C.A., ed. Methods of soil analysis. Madison, American Society of Agronomy, 1965. p.299-314. 